\title{
Mentholated cigarettes and non-lung smoking related cancers in California, USA
}

\author{
Gary D Friedman, Marianne Sadler, Irene S Tekawa, Stephen Sidney
}

We sought to discover if the higher risk among men of lung cancer associated with mentholated than with plain cigarettes ${ }^{1}$ applied as well to other smoking related cancers (upper aerodigestive: mouth, pharynx, larynx, oesophagus; pancreas, renal adenocarcinoma, other urinary tract (urothelium), cervix). In 1979-1985, 79946 subscribers of the Kaiser Permanente Medical Care Program in northern California, age 30-89 years, completed a detailed questionnaire about smoking habits ${ }^{2}$ and were followed up through 1994. We here focus on 5770 men and 5990 women (58 438 and 63775 person years, respectively) who reported cigarette smoking currently and for at least 20 years at the time of completing the questionnaires and who were free of smoking related cancers at entry and who had recorded whether their current cigarette was mentholated. ${ }^{1}$ Compared with never smokers (14 409 men and 25402 women) the rate ratio (95\% confidence intervals (CIs)) for all of these long term smokers, of developing any of these non-lung cancers was $3.22(2.55,4.08)$ among men, and 2.23 (1.80, 2.76) among women. These and the mentholated/plain rate ratios and confidence intervals were calculated by the MantelHaenszel method adjusting for age. The numbers of mentholated cigarette smokers and plain cigarette smokers were, men: 1579 and 4191, women: 2075 and 3915, respectively.

Risk was not increased among persons who currently smoked mentholated compared with plain cigarettes for all of the non-lung smoking related cancers combined or for most sites studied. Two modestly increased rate ratios had $95 \%$ confidence intervals that widely overlapped 1.0 (table 1). Results were similar when current smokers of mentholated and plain cigarettes were restricted, respectively, to persons who reported smoking mentholated ciga-

ccepted for publication 23 September 1997 rettes for at least 10 years and for less than six months. We also looked at prostate cancer because of its higher risk among African Americans, who also select mentholated cigarettes more than the white population ${ }^{3}$ and found no statistically significant excess risk associated with mentholation, both in these analyses not controlled for race (rate ratio 1.15, CIs $0.82,1.62$ ) and in Cox proportional hazards regression controlling for age and race (rate ratio 1.12 , CIs $0.80,1.58$ ).

Possible mechanisms for an increased risk of lung cancer associated with mentholation include greater inhalation of smoke because of menthol's subjective cooling or anaesthetising effects and increased absorption of carcinogens. ${ }^{1}$ Jarvik $e t ~ a l^{4}$ found no greater inhalation but did observe increased absorption of carbon monoxide from mentholated cigarettes. If absorption of carcinogens were also greater, risk of smoking induced cancers at non-lung sites might be expected to increase.

Why did these findings differ from those for lung cancer? ${ }^{1}$ Although statistical power was low for individual sites, the total number of smoking related cancers among men, 163, approximated their 160 lung cancers. ${ }^{1}$ Cancers in more distant organs may be less influenced by the effects of mentholation on smoking topography or on the absorption of smoke components than are lung cancers. Mentholation may have cancer promoting effects on tissue of the lungs but not of other organs. This would not be simply a matter of direct versus indirect contact because direct contact also occurs with the mucosa of the mouth, pharynx and larynx, the sites of most of the upper aerodigestive cancers, which showed no association with mentholation here, or in a study of oral and pharyngeal cancer, looking at these two sites combined. ${ }^{5}$ Finally, the association of mentholation with lung cancer in this study population may be merely a chance finding, particularly as it was absent in women ${ }^{1}$ and has not been replicated elsewhere.

Funding: supported by National Cancer Institute grant R35 CA 49761.

Conflicts of interest: none.

1 Sidney S, Tekawa IS, Friedman G D, Sadler M C, Tashkin D P. Mentholated cigarette use and lung cancer. Arch Intern Med 1995;155:727-32.

2 Friedman GD, Sidney S, Polen MR. Smoking habits among multiphasic examinees, 1979-1984. West f Med 1986;145: 651-6.

3 Sidney S, Tekawa I, Friedman GD. Mentholated cigarette use among multiphasic examinees, 1979 to $1986 . \mathrm{Am} \mathcal{F}$ Public Health 1989;79:1415-16.

4 Jarvik ME, Tashkin DP, Caskey NH, McCarthy WJ, Rosenblatt MR. Mentholated cigarettes decrease puff volume of smoke and increase carbon monoxide absorption. Physiol smoke and increase carb

5 Kabat GC, Hebert JR. Use of mentholated cigarettes and oropharyngeal cancer. Epidemiology 1994;5:183-8. 